\title{
Explicit and Implicit Memory in Depressive Patients. Review of the Literature
}

\author{
Chrystel Besche-Richard ${ }^{1,2}$ \\ ${ }^{1}$ Laboratoire Cognition, Santé, Socialisation, C2S EA 6291, Université de Reims Champagne-Ardenne, \\ Reims, France \\ ${ }^{2}$ Institut Universitaire de France, Paris, France \\ Email: chrystel.besche@univ-reims.fr
}

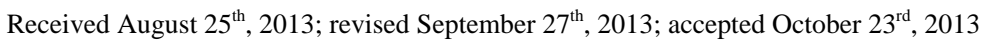

\begin{abstract}
Copyright (C) 2013 Chrystel Besche-Richard. This is an open access article distributed under the Creative Commons Attribution License, which permits unrestricted use, distribution, and reproduction in any medium, provided the original work is properly cited.
\end{abstract}

\begin{abstract}
The cognitive approach to depressive disorders has generally focused on memory problems. In recent years, research conducted in this field has been based on new cognitive theories of memory that distinguish between implicit memory, i.e. an unconscious memory that promotes the use of automatic processes, and explicit memory, i.e. a conscious memory based on the use of controlled processes. Here, we propose a review of the literature concerning the studies of depressive pathology. The initial results suggested a specific impairment of the explicit memory and thus brought depressive pathology into the realm of the pathologies of consciousness. More recent results and/or a consideration of divergent findings have led researchers to revise this interpretation. After looking at the various studies, we shall point out certain divergent results that will allow us to propose some new explanations and, finally, some new avenues of research based on the consideration of clinical and methodological elements. This approach is based on a cognitive and clinical examination of depressive disease. We examine the role of the processes-data-or conceptually driven processes, the role of the paradigm used, and clinical profile with a special interest for the presence of anxious or psychotic symptoms, and for the emotional profile.
\end{abstract}

Keywords: Depression; Implicit Memory; Explicit Memory; Recognition; Recall; Cognition

\section{Introduction}

Depression is characterized by a constellation of behavioral, emotional, and cognitive symptoms especially in the domain of memory (Gotlib \& Joormann, 2010; Schaub et al., 2013). Memory disorders in major depressive episodes have attracted much interest with the development of new cognitive models that distinguish between implicit and explicit measures of memory. These two types of memory, initially revealed through the study of amnesic patients, correspond to an unconscious and automatic form of memory (implicit memory) and a conscious, strategy form that requires the intervention of controlled processes (explicit memory).

What is the likely value of conducting a review of the literature on implicit and explicit memory functioning in the field of depressive pathology? This exercise is underpinned by a number of theoretical, methodological and clinical reasons. In effect, even though the results reported to date support a number of robust hypotheses, certain divergent results that primarily relate to the functioning of implicit memory in these patients still need to be accounted for. Furthermore, we consider that the recent methodological advances achieved in the exploration of the implicit and explicit forms of memory in normal individuals will also make it possible to advance our understanding of depressed patients.

This article therefore consists of three sections: firstly, we shall review the published studies that deal with implicit and explicit memory functioning in depressed patients; secondly, we shall present the reasons thought to account for certain divergent results; finally, we shall make a number of propositions that we believe will allow us to advance our understanding of memory impairments in depressed patients and their links with the clinical description of depression.

\section{Is Depression a Pathology of Consciousness?}

The impairment of memory functions was pointed out in clinical descriptions of depressive disorders at a very early stage. The first studies, conducted as of the 1970s (Calev \& Erwin, 1985; Calev, Korin, Shapira, Kugelmass, \& Lerer, 1986; Cohen, Weingartner, Smallberg, Pickar, \& Murphy, 1982; Dunbar \& Lishman, 1984; Golinkoff \& Sweeney, 1989; Hartlage, Alloy, Vasquez, \& Dykman, 1993; Henry, Weingartner, \& Murphy, 1973; Johnson \& Magaro, 1987; Roy-Byrne, Weingartner, Bierer, Thompson, \& Post, 1986; Sternberg \& Jarvik, 1976; Stromgren, 1977; Weingartner, Cohen, Murphy, Martello, \& Gerdt, 1981), focused on exploring the explicit functioning of memory in depressed patients and indicate the difficulties encountered by these patients when presented with traditional memory tasks. The differences between depressed patients and control participants seem to be greater in free recall than in cued recall tasks (Cohen et al., 1982). Furthermore, recall is poorer in depressed patients when they are required to develop elaborate strategies during the encoding phase. According to the authors, these results suggest a deficit in the spontaneous use of certain encoding strategies (Channon, Baker, \& Roberton, 
1993; Watts, Dalgleish, Bourke, \& Healy, 1990; Weingartner et al., 1981) which may nevertheless be effectively mobilized in other situations (Hertel \& Rude, 1991). However, not all the explicit memory tasks have resulted in the observation of impairments in depressed patients: no systematic difference between the performances of depressed patients and control participants have been observed in recognition tasks (Calev \& Erwin, 1985; Dunbar \& Lishman, 1984; Golinkoff \& Sweeney, 1989; Miller \& Lewis, 1977), with performances generally being more impaired when recall is delayed (Ellwart, Rink, \& Becker, 2003). These results have been confirmed by more recent studies as one of Fossati et al. (2004) who showed an impairment of free recall contrary to preserved cued recall and recognition in major depressive patients.

The 1990s saw the first investigations of implicit memory in connection with depression, resulting in studies that compared implicit and explicit memory performances in this clinical population. We shall therefore present the results of studies published between 1990 and 2013 that have investigated the operation of implicit and explicit memory in relation with thymic disorders. The first study was conducted by Hertel and Hardin (1990) who compared memory performances in a homophone spelling task and a recognition task. This initial study was not conducted using a clinical population of patients meeting the current diagnostic criteria for a major depressive episode but, instead, among students who were asked to complete a self-questionnaire for the evaluation of depression following the induction of a depressive or neutral mood. The results reveal dissociation between the performances as a function of the implicit or explicit nature of the tasks used. In effect, the performances of the two participant groups did not differ on the homophone spelling task (implicit task), unlike in the recognition task (explicit task). This dissociation has been confirmed by the results of a number of other studies (Bazin, Perruchet, De Bonis, \& Féline, 1994; Beato \& Fernández, 1995; Danion,
Willard-Schroeder, Zimmermann, Grangé, Schlienger, \& Singer, 1991; Jenkins \& McDowall, 2001). Unlike Hertel and Hardin's work (1990), these studies have generally called upon groups of depressed patients, hospitalized and recruited in accordance with standardized diagnostic criteria. The patients who took part on these studies were severely depressed at the time of their inclusion, as the high scores they obtained in the employed clinical evaluation scales testify (see Table 1).

Only one study has reported divergent results: this is the study conducted in 1992 by Elliott and Greene that made use of a set of four memory tasks consisting of two implicit tasks (completion of trigrams, homophone spelling) and two explicit tasks (free recall and cued recall). The patients exhibited more severe memory disorders than those found in the other studies because their performances were impaired in the explicit as well as the implicit tasks. This result may first of all be explained by the contamination phenomena related to the subjects' use of explicit retrieval strategies during implicit recovery. If this is the case, then the implicit memory impairments revealed in the depressed patients may be explained by their poorer use of these strategies in the employed tasks. In their review of the literature on implicit memory functioning in depressed patients, Roediger and McDermott (1992) discuss this result at length and propose a number of interpretations. First of all, these authors point out a methodological bias that relates to the evaluation of the baseline for the stimuli that were not studied since Elliott and Greene (1992) did not use the traditional procedure which consists of counterbalancing the studied versus non-studied items in the experimental design but, instead, used normative data from the literature in order to evaluate this baseline. This methodological specificity might therefore go some way to explaining the performances observed in the depressed patients on the implicit tasks. Finally, Roediger and McDermott refer to the nature of the cognitive processes mobilized by the task-data-driven or conceptually-driven processes

Table 1.

Characteristics of the studied population and mean scores in the clinical scales obtained by the participants in the various cited studies.

\begin{tabular}{|c|c|c|}
\hline & Studied population & Mean scores in the clinical scales \\
\hline Bazin et al., 1994 & 23 depressed patients, 37 control subjects matched for gender, age and academic level & MADRS: 35.26; BDI: 21.3 \\
\hline Beato \& Fernández, 1995 & $\begin{array}{c}24 \text { depressed subjects, } 24 \text { control subjects doubtlessly } \\
\text { not matched on age ( } 35.1 \text { vs. } 27.7 \text { ) and gender }\end{array}$ & BDI: 23 (for the controls: 3.46) \\
\hline Danion et al., 1991 & 18 depressed patients, 18 control subjects matched for gender, age and academic level & HDRS: 29.6 \\
\hline Elliott \& Greene, 1992 & 10 depressed patients, 10 control subjects matched for gender, age and academic level & HDRS: 27.3 \\
\hline Hertel \& Hardin, 1990 & $\begin{array}{l}\text { Experiments } 1 \text { \& 2: } 48 \text { (experiment } 1 \text { ) and } 34 \text { (experiment 2) psychology students } \\
\text { whose score on the BDI was less than or equal to 6, followed } \\
\text { by the induction of a neutral or depressed mood. } \\
\text { Experiment 3: } 91 \text { psychology students divided into } 3 \text { groups: naturally depressed } \\
\text { (BDI > 9), induction of a neutral mood, - not depressed (BDI }<6 \text { ), } \\
\text { induction of a neutral or depressed mood. }\end{array}$ & $\begin{array}{l}\text { In experiments } 1 \& 2 \text {, there was no } \\
\text { significant difference on the BDI score } \\
\text { following the induction of a neutral or } \\
\text { depressed mood }\end{array}$ \\
\hline Hertel \& Milan, 1994 & $\begin{array}{l}89 \text { students evaluated using the BDI two weeks before their participation; } \\
\text { Two groups: dysphoric (BDI > 9), non dysphoric (BDI < 7) evaluated again } \\
\text { with the BDI after completing the memory tasks and with the STAI }\end{array}$ & $\begin{array}{l}\text { Dysphoric: } 1 \text { ) BDI: } 17.1 \text { to } 17.7 \text {, } \\
\text { 2) STAI state: } 48.7 \text { to } 53.3 \text {, } \\
\text { 3) STAI trait: } 51.5 \text { to } 53.2 \text {. } \\
\text { Non dysphoric: } 1 \text { ) BDI: } 3.2 \text { to } 4.9 \text {, } \\
\text { 2) STAI state: } 36.1 \text { to } 40.5 \text {, } \\
\text { 3) STAI trait: } 35.7 \text { to } 39.3 \text {. }\end{array}$ \\
\hline Jenkins \& McDowall, 2001 & 10 depressed patients,10 control subjects matched for age and academic level & BDI: 25.4 (for the control: 2.1) \\
\hline Mulligan, 2011 & 66 subclinically depressed patients and their 66 controls & BDI: 16.3 (for the controls: 2) \\
\hline
\end{tabular}

Note: BDI: Beck Depression Inventory; HDRS: Hamilton Depression Rating Scale; MADRS: Montgomery and Asberg Depression Rating Scale; STAI: State-Trait Anxiety Inventory. 
—as the source of the impairment of implicit performances in the depressed patients.

In the light of all these results, it currently seems difficult to accept the idea that depressive pathology results in conscious memory impairments and could therefore be qualified as pathology of consciousness. If the initial results suggest the existence of a specific impairment of explicit memory that takes the form of a degradation of the conscious system (Bazin et al., 1994; Danion et al., 1991; Hertel \& Hardin, 1990; Hertel \& Milan, 1994), more recent data (Beato \& Fernández, 1995; Jenkins \& McDowall, 2001), even if it does not completely invalidate this conclusion, indicates that the impairment of memory functioning in depressed patients may be more global and also affect implicit performances. It would appear that the opposition between implicit and explicit memory is not sufficient to explain all the results observed in depressed patients. In effect, the results obtained by Beato and Fernández (1995) \& Jenkins and McDowall (2001) provide arguments in favor of the functional theories of memory. However, there are not as yet sufficient results available in this field to allow us to hypothesize that there is a specific impairment of the conceptually-driven processes in depressed patients (see Table 2). It should nevertheless be remembered that Elliott and Greene (1992) observed an impairment of implicit perceptual memory in the depressed patients in their study. Furthermore, in order to evaluate explicit memory these authors, like Bazin et al. (1994), used a familiar cued recall task in order to mobilize the datadriven processes rather than the conceptual processes but that, despite this, the depressed patients continued to exhibit deficits.

\section{Summary of the Results on Implicit and Explicit Memory Functioning in Depressed Patients: Limitations of the Studies}

Overall, the studies indicate, in a fairly stable way, an im- pairment of explicit memory in depressed patients. The results obtained by Beato and Fernández (1995) \& Jenkins and McDowall (2001) emphasize the fact that the hypo-functioning of implicit memory is probably due to the impairment and/or underuse of the conceptual processes, i.e. mechanisms that are primarily mobilized in explicit tasks. If we accept the conclusions formulated by these authors, according to whom memory tests that are based on conceptually-driven information processing should be more greatly affected by depressive pathology than those that are based on data-driven processing, then the dissociation of performances should take the form of a dissociation between impaired conceptual processes and preserved data-driven processes and not between implicit and explicit memory performances. This would then mean that the datadriven processes are preserved in depressed patients. The summary of the obtained results runs counter to this conclusion since we have seen that performances in explicit perceptual tasks are also impaired in depressed patients. Nevertheless, no comparison of a perceptual and a conceptual form of explicit memory has ever been undertaken in depressed patients (only on dysphoric population by Elliott \& Greene, 1992) within the framework of one and the same study.

Even though the results concerning the explicit evaluation of memory in depressed patients are relatively consistent, the key area of divergence relates to the performances observed in free recall and recognition tasks since anomalies have rarely been identified in depressed patients in this latter type of task.

Even though they belong to the group of explicit tasks, recognition tasks differ from the recall tasks in terms of the processes that they mobilize. As early as the 1970s, Kintsch argued that different cognitive processes are involved in recall and recognition tasks. In a classic recall task, the subject first generates the candidate items that have previously been activated and then seeks the candidate that was seen during the encoding phase (generation-recognition model). In a recognition task,

Table 2.

Tasks Used and Type of Mobilized Processes in the Various Cited Studies.

\begin{tabular}{|c|c|c|c|}
\hline Studies & Tasks used & Type of task/type of mobilized process & Results \\
\hline Bazin et al., 1994 & $\begin{array}{l}\text { 1) Trigram completion } \\
\text { 2) Cued recall }\end{array}$ & $\begin{array}{l}\text { 1) Implicit memory/Data-driven } \\
\text { 2) Explicit memory/Data-driven }\end{array}$ & $\begin{array}{l}\mathrm{D}=\mathrm{C} \\
\mathrm{D}<\mathrm{C}\end{array}$ \\
\hline Beato \& Fernández, 1995 & $\begin{array}{l}\text { 1) Word fragment completion } \\
\text { 2) Category production } \\
\text { 3) Free recall }\end{array}$ & $\begin{array}{l}\text { 1) Implicit memory/Data-driven } \\
\text { 2) Implicit memory/Conceptually-driven } \\
\text { 3) Explicit memory/Conceptually-driven }\end{array}$ & $\begin{array}{l}\mathrm{D}=\mathrm{C} \\
\mathrm{D}<\mathrm{C} \\
\mathrm{D}<\mathrm{C}\end{array}$ \\
\hline Danion et al., 1991 & $\begin{array}{l}\text { 1) Trigram completion } \\
\text { 2) Free recall }\end{array}$ & $\begin{array}{l}\text { 1) Implicit memory/Data-driven } \\
\text { 2) Explicit memory/Conceptually-driven }\end{array}$ & $\begin{array}{l}\mathrm{D}=\mathrm{C} \\
\mathrm{D}<\mathrm{C}\end{array}$ \\
\hline Elliott \& Greene, 1992 & $\begin{array}{l}\text { 1) Trigram completion } \\
\text { 2) Homophone spelling } \\
\text { 3) Cued recall } \\
\text { 4) Free recall }\end{array}$ & $\begin{array}{l}\text { 1) Implicit memory/Data-driven } \\
\text { 2) Implicit memory/Data-driven } \\
\text { 3) Explicit memory/Data-driven } \\
\text { 4) Explicit memory/Conceptually-driven }\end{array}$ & $\begin{array}{l}\text { Dys }<\text { C } \\
\text { Dys }<\text { C } \\
\text { Dys }<\text { C } \\
\text { Dys }<\text { C }\end{array}$ \\
\hline Hertel\& Hardin, 1990 & $\begin{array}{l}\text { 1) Homophone spelling } \\
\text { 2) Recognition }\end{array}$ & $\begin{array}{l}\text { 1) Implicit memory/Data-driven } \\
\text { 2) Explicit memory/Data-driven }\end{array}$ & $\begin{array}{l}\text { Dys }=\mathrm{C} \\
\text { Dys }<\mathrm{C}\end{array}$ \\
\hline Hertel\& Milan, 1994 & Process Dissociation Procedure (PDP) & $\begin{array}{l}\text { 1) Recollection (conceptually-driven) } \\
\text { 2) Familiarity (Data-driven) }\end{array}$ & $\begin{array}{l}\text { Dys }<\text { C } \\
\text { Dys }=\text { C }\end{array}$ \\
\hline Jenkins \& McDowall, 2001 & $\begin{array}{l}\text { 1) Category association } \\
\text { 2) Word fragment completion } \\
\text { 3) Free recall }\end{array}$ & $\begin{array}{l}\text { 1) Implicit memory/Conceptually-driven } \\
\text { 2) Implicit memory/Data-driven } \\
\text { 3) Explicit memory/Conceptually-driven }\end{array}$ & $\begin{array}{l}\mathrm{D}<\mathrm{C} \\
\mathrm{D}=\mathrm{C} \\
\mathrm{D}<\mathrm{C}\end{array}$ \\
\hline Mulligan, 2011 & $\begin{array}{l}\text { 1) Category production } \\
\text { 2) Category cued-recall }\end{array}$ & $\begin{array}{l}\text { 1) Implicit memory/Conceptually-driven } \\
\text { 2) Explicit memory/Conceptually-driven }\end{array}$ & $\begin{array}{c}\text { Dys }<\text { C if test-aware } \\
\text { Dys }<\mathrm{C}\end{array}$ \\
\hline
\end{tabular}

Note: D: Depressed patients; C: Control participants; Dys: Dysphoric participants. 
this search phase is replaced by a faster mechanism that directly identifies the words seen during the training phase. The data provided by Johnston, Dark, and Jacoby (1985) indicates that two processes are involved in recognition tasks: on the one hand, a process based on a feeling of familiarity and, on the other, an active search mechanism that results in a memory effect. The latter process would only occur in recognition tasks if the former were to prove to be inadequate (Mandler, 1980). The search mechanism, which is an elaborated, integrative process, would therefore be optional as far as recognition performance is concerned and would depend on the conditions obtaining in the situation in question. The results of studies of the neuroanatomy of memory that have revealed the activation of different areas of the brain as a function of the nature of the administered task (Cabeza, Kapur, Craick, \& McIntosh, 1997) argue in favor of differences between recall and recognition tasks. Furthermore, this study emphasizes the fact that recognition tasks are more perceptual than recall tasks. According to certain authors, the selective deficit in recall performances observed among depressed patients suggests an impairment of the memory search and retrieval mechanisms (Fossati, Coyette, Ergis, \& Allilaire, 2002; Ilsley, Moffoot, \& O’Carroll, 1995).

Let us turn now to the clinical factors that might have an impact on the nature of depressed patients' memory performances and whose role cannot be ignored in the interpretation of the results. Only in very few studies, have cognitivo-clinical correlations between implicit and explicit memory performances and certain clinical factors related either directly or indirectly to the depressive syndrome been conducted. Only four studies have addressed the respective roles of anxiety and depression in memory performance. All of these studies were conducted using emotionally valenced material in order to evaluate the cognitive processing performed by subjects with regard to words with a positive, negative (inducing depression or anxiety) or neutral affective valence. Three of these studies used a categorical, non-dimensional clinical approach that compared groups of anxious patients with groups of depressed patients (Bradley, Mogg, \& Williams, 1994, 1995; Tarsia, Power, \& Sanavio, 2003). The results reveal that memorized information is processed differently depending on the semantic context of the words and, furthermore, the clinical characteristics of the patients (preferential treatment of depression-inducing words in the depressed patients and preferential treatment of the anxietyinducing words in the anxious patients). The results obtained by Tarsia et al. (2003), when considered independently of the affective valence of the material, demonstrate the cognitive differences associated with the specific clinical profiles since, in their anxious participants, the authors observed an increase in the priming effect in the implicit task (impairment of the automatic processes) and, in the depressed subjects, a fall-off in recall performances (impairment of the controlled processes). These results therefore suggest that specific emotional dimensions can modify the processing of the information that is to be memorized and does so as a function of the implicit or explicit nature of the employed task. We can ask ourselves to what extent the dimension of anxiety, when associated with a major depressive episode, might modify patients' memory performance profiles and result in not only a disruption of their explicit but also of their implicit performances, especially when the tasks involved are conceptual in nature. This consideration could explain some of the results presented above. As far as we know, only very few studies have addressed the role of clinical elements such as affective blunting, psychomotor slowing or anxiety on the memory performances of depressed patients. However, it would appear that these dimensions have a harmful effect on certain cognitive functions.

\section{Current Research into the Evaluation of Memory in Depression: Some Methodological Propositions}

In this section, we shall return to the various points set out above that we consider to be relevant for a more thorough and better examination of memory functions in depressed patients.

First of all, we should like to return to the distinction between perceptual and cognitive processes used in implicit and explicit memory tasks. It appears that these different processes are able to modify the performances of depressed patients in implicit and explicit memory tasks. It would therefore seem to be useful, following what has already been done among patients with schizophrenia (Schwartz, Rosse, \& Deutsch, 1993), to use this dual dissociation in a group of depressed patients on the basis of four memory tasks: word identification (data-driven implicit memory test), cued recall (trigram completion: datadriven explicit memory test), category production task (conceptually-driven implicit memory test) and free recall (conceptually-driven implicit memory test). The hypothesis formulated on the basis of the functional theories of memory supposes that the conceptually-driven processes are impaired in depressed patients whatever the mode used to investigate memory (implicit or explicit). As we have seen earlier, the results that are currently available for such patients do not all confirm this assumption.

We saw above that the contamination of implicit memory performances by explicit processes could, to some extent, explain the divergent results obtained by certain studies that have revealed an impairment of implicit memory functioning in depressed patients. In 1990, Bowers and Schacter used a questionnaire administered after a trigram completion task to show that a certain number of their participants were fully aware of the link between the encoding and the test phase. Mulligan (2011), in a brief report, showed that conceptually-driven implicit performance were lower in subclinical depressed individuals than controls only when participants were test-aware.

Another way to overcome this bias would be to use techniques that attempt to reduce this awareness by employing, among other things, appropriate instructions, specific encoding and/or interfering tasks. To this end, Jacoby (1991) developed a special procedure, the process dissociation procedure (PDP), that permits improved control of the memory strategies used by the participants. In one condition (inclusion), the use of the PDP permits the automatic and controlled processes to work together, whereas in another condition (exclusion) their respective actions can be contrasted. In this latter condition, participants are obliged to resort to controlled processes, thus ensuring that the obtained effects are due only to the controlled processes. The inclusion condition consists of an explicit memory test in which the instructions require the participants to guess when they are unable to remember. The exclusion condition consists of a test in which the subjects are told not to name a previously studied item as their response. This procedure has already been used in the study of depression (Hertel \& Milan, 1994; McQueen et al., 2002). McQueen et al. (2002) showed dissociation between automatic and controlled memory in depressed 
participants, with controlled processes altered. Moreover, McQueen et al. (2002) showed that this deficit was more related to the number of past depressed episodes than to current mood state.

The application of the PDP, as formulated by Jacoby, to psychiatric patients, and in particular severely depressed patients, would seem to a problematic undertaking given that such patients are known to tire very quickly. In effect, one of the reasons for the difficulty of using the standard procedure lies in the application of the experimental design during which the inclusion and exclusion tests follow one another in a random order during one and the same block of trials in the test phase. This implies that the two instructions (inclusion and exclusion) are maintained in memory since the subjects regularly have to change from one instruction to the other. This, on its own, represents a severe cognitive load for subjects whose information processing is slowed and who exhibit memory difficulties. Thus, in order to apply this method to depressed patients, we suggest using a simplified procedure that has already been employed by Cermak, Verfaellie, Swenney, and Jacoby (1992) among a population of amnesic patients and which makes use of perceptual tasks that have been adapted for the conceptual mode by Besche-Richard, Passerieux, Nicolas, Laurent, and Hardy-Baylé (1999) for use in the study of schizophrenic disorders. Furthermore, this simplified methodology makes it possible to evaluate conscious memory by testing the establishment of a specific controlled mechanism, namely inhibition, which a number of studies have found to be ineffective in depressed patients (Benoit, Fortin, Lemelin, \& Laplante, 1992; Fossati, Ergis, \& Allilaire, 2002).

The use of the paradigm developed by Tulving (1985) to take account of two forms of recognition on the basis of introspective responses would make it possible to identify more clearly the explicit processes that are impaired and gain a better understanding of these subjects' recognition performances. When participants use active memory retrieval mechanisms, they find the information that is to be recovered and this memory integrates the contextual elements that accompanied the encoding of the information. In contrast, when recognition is based on a feeling of familiarity, subjects know that they have already seen the information but are unable to specify the associated contextual elements. This opposition was operationalized for the first time by Tulving (1985) in the R/K (Remember/Know) paradigm and then subsequently taken up by Gardiner and Java (1993). In this paradigm, participants taking part in a recognition task are asked to determine the nature of their psychological experience associated with the recognition of each recognized item. If the previously presented item is recognized very clearly, then the participants have to give the response $\mathrm{R}$ to indicate that they can clearly remember the circumstances under which the item was studied, i.e. they are able to provide the associated details. However, if the participants are sure of having studied the target item but are unable to evoke a precise memory in connection with it then they must respond $\mathrm{K}$ to indicate simply that they have no doubts concerning the material but cannot provide any details concerning the context associated with its presentation. In the model initially proposed by Tulving, the $\mathrm{R}$ and $\mathrm{K}$ responses were associated with two different states of consciousness: $\mathrm{R}$ responses refer to autonoetic consciousness while $K$ responses are associated with noetic consciousness. Within the framework of the "win-process" theories presented above, the authors suggest that $\mathrm{K}$ responses are based on perceptual processing or even on automatic information processing mechanisms whereas the $\mathrm{R}$ responses would tend to reflect explicit, conceptually-driven processes, or indeed active, or even strategic, search processes based on the learning context.

This paradigm seems to be of great interest for the investigation of memory impairments in depressed patients. This paradigm has been used only in two studies (Ramponi et al., 2004; Drakeford et al., 2010). Depressed patients displayed lower levels of Remember for verbal and neutral facial stimuli contrary to Know judgments, and these memory performances were related to the number of past depressive episodes. These results support the hypothesis that memory deficits in depressed patients are associated with a deficient recollection and a preserved familiarity processes (Drakeford et al., 2010). Ramponi et al. (2004) have found a same set of results in a dysphoric population.

Finally, we suggest that more attention should be paid to the clinical factors that may influence the nature of the cognitive performances observed in depressed patients. As far as the trait vs. state character of the memory difficulties observed in depressed patients are concerned, the studies conducted by Bazin et al. (1994) \& Bazin, Perruchet, and Féline (1996) are informative since they indicate that the impairments of explicit memory can be attenuated by favorable clinical developments. Furthermore, Channon et al. (1993) as well as Danion et al. (1991) failed to reveal any differences in the memory functioning of patients who were or were not receiving psychotropic treatment. It therefore appears that the administration of a biochemical treatment is not responsible for the memory impairments observed in depressed patients. This conclusion is substantiated by the results obtained by Bazin et al. $(1994,1996)$ in which the improvement in the performances observed some time after the acute episode related to patients who were still receiving psychotropic treatment. It would appear that the recurrence of major depressive episodes is associated with poor recall performances unlike what has been observed in patients suffering from their first depressive episode (Fossati, Coyette, Ergis, \& Allilaire, 2002; Fossati et al., 2004).

Above, we stressed the importance of the anxiety dimension for memory performance. It seems to us that not enough attention has been paid to this dimension in studies of depressed patients even though it is a clinical dimension that exists in a high proportion of them. There is considerable overlap between anxiety and depressive disorders, which is also expressed in a certain degree of similarity in symptomatology, etiology, vulnerability factors (Drost et al., 2012). Similarly, factors such as psychomotor slowing, affective blunting or the possible presence of psychotic symptoms might very well interfere with implicit and/or explicit memory functioning. We know that patients with psychotic symptoms present more severe illness, were predictive of lack of remission (Buoli, Caldiroli, \& Altamura, 2013) and present more cognitive impairment than nonpsychotic major depressives for attention and executive functioning (Schatzberg et al., 2000). It should be recalled that a link between certain cognitive disorders observed in depressed patients and various clinical dimensions has been established (for example, executive deficits and psychotic symptoms, Fossati, Ergis, \& Alillaire, 2002; disappearance of the P3a component [that indexes the automatic processing of information] from the fronto-central sites in depressed patients who are characterized by a high level of affective blunting and significant 
psychomotor slowing; in contrast, this P3a component is present in depressed patients with a clinical description that is characterized by a high level of anxiety and an impulsive dimension, Partiot, Pierson, Le Houezec, Dodin, Renault, \& Jouvent, 1993; Partiot, Pierson, Renault, Widlöcher, \& Jouvent, 1994; similar data has been obtained on the CNV [Contingent negative variation] by Pierson et al., 1994). This data therefore suggests that depression is not a homogeneous category either at the cognitive or the clinical level. Depending on the dominant clinical dimensions, it is likely that different cognitive processes are impaired or preserved in depression. This general observation undoubtedly also applies to memory performances.

\section{Conclusion}

Memory disorders are an important component of the clinical symptoms of depression. A specific neuropsychological evaluation is an essential point in regard to the clinical profile (anxious or psychotic symptoms associated) of depression and the methodology of investigation of explicit and implicit memory. In the future, in addition to the orientations mentioned above, it is clear that the study of episodic memory in depression will be linked to other cognitive functions such as self-identity (Sperdurti et al., 2013), social cognition and metacognition (Rabin et al., 2013). Finally, a better understanding of mnemonic function in depressive illness will permit to develop specific methods of cognitive remediation (Lee et al., 2013).

\section{REFERENCES}

Bazin, N., Perruchet, P., De Bonis, M., \& Féline, A. (1994). The dissociation of explicit and implicit memory in depressed patients. Psychological Medicine, 24, 239-245.

http://dx.doi.org/10.1017/S0033291700027008

Bazin, N., Perruchet, P., \& Féline, A. (1996). Mood congruence effect in explicit and implicit memory tasks: a comparison between depressed patients, schizophrenic patients and controls. European Psychiatry, 11, 390-395.

http://dx.doi.org/10.1016/S0924-9338(97)82575-8

Beato, M. S., \& Fernández, A. (1995). Memoriaexplicícita e implícita en pacientesdepresivos: Diferencias entre pruebasperceptivas y conceptuales. Cognitiva, 7, 51-66.

http://dx.doi.org/10.1174/021435595321250508

Benoit, G., Fortin, L., Lemelin, S., \& Laplante, L. (1992). Selective attention in major depression: Clinical retardation and cognitive inhibition. Canadian Journal of Psychology, 46, 41-52. http://dx.doi.org/10.1037/h0084314

Besche-Richard, C., Passerieux, C., Nicolas, S., Laurent, J.-P., \& Hardy-Baylé, M.-C. (1999). Fluency versus conscious recollection in category-production. The performance of schizophrenic patients. Brain and Cognition, 39, 100-115. http://dx.doi.org/10.1006/brcg.1998.1061

Bowers, J. S., \& Schacter, D. L. (1990). Implicit memory and test awareness. Journal of Experimental Psychology: Learning, Memory, and Cognition, 16, 404-416. http://dx.doi.org/10.1037/0278-7393.16.3.404

Bradley, B. P., Mogg, K., \& Williams, R. (1994). Implicit and explicit memory for emotional information in non-clinical subjects. Behaviour Research and Therapy, 32, 65-78. http://dx.doi.org/10.1016/0005-7967(94)90085-X

Bradley, B. P., Mogg, K., \& Williams, R. (1995). Implicit and explicit memory for emotional-congruent information in clinical depression and anxiety. Behaviour Research and Therapy, 33, 755-770. http://dx.doi.org/10.1016/0005-7967(94)90085-X

Buoli, M., Caldiroli, A., \& Altamura, A. C. (2013). Psychotic versus non-psychotic major depressive disorder: A comparative naturalistic study. Asian Journal of Psychiatry, 6, 333-337. http://dx.doi.org/10.1016/j.ajp.2013.02.003

Cabeza, R., Kapur, S., Craick, F. I. M., \& McIntosh, A. R. (1997). Functional neuroanatomy of recall and recognition: A PET study of episodic memory. Journal of Cognitive Neuroscience, 9, 254-265. http://dx.doi.org/10.1162/jocn.1997.9.2.254

Calev, A., \& Erwin, P. G. (1985). Recall and recognition in depressives: Use of matched tasks. British Journal of Clinical Psychology, 24, 127-128. http://dx.doi.org/10.1111/j.2044-8260.1985.tb01323.x

Calev, A., Korin, Y., Shapira, B, Kugelmass, S., \& Lerer, B. (1986). Verbal and non-verbal recall by depressed and euthymic affective patients. Psychological Medicine, 16, 789-794. http://dx.doi.org/10.1017/S0033291700011806

Cermak, L. S., Verfaellie, M., Swenney, M., \& Jacoby, L. L. (1992). Fluency versus conscious recollection in the word completion performance of amnesic patients. Brain and Cognition, 20, 367-377. http://dx.doi.org/10.1016/0278-2626(92)90027-J

Channon, S., Baker, J. E., \& Robertson, M. M. (1993). Effects of structure and clustering on recall and recognition memory in clinical depression. Journal of Abnormal Psychology, 102, 323-326. http://dx.doi.org/10.1037//0021-843X.102.2.323

Cohen, R. M., Weingartner, H., Smallberg, S. A., Pickar, D., \& Murphy, D. L. (1982). Effort and cognition in depression. Archives of General Psychiatry, 39, 593-597.

http://dx.doi.org/10.1001/archpsyc.1982.04290050061012

Danion, J.-M., Willard-Schroeder, D., Zimmermann, A., Grangé, D., Schlienger, J.-L., \& Singer, L. (1991). Explicit memory and repetition priming in depression: Preliminary findings. Archives of General Psychiatry, 48, 707-711. http://dx.doi.org/10.1001/archpsyc.1991.01810320031005

Drakeford, J. L., Edelstyn, N. M. J., Oyebode, F., Srivastava, S., Calthorpe, W. R., \& Mukherjee, T. (2010). Recollection deficiencies in patients with major depressive disorder. Psychiatry Research, 175, 205-210. http://dx.doi.org/10.1016/j.psychres.2008.08.010

Drost, J., Van der Does, A. J. W., Antypa, N., Zitman, N. G., Van Dyck, R., \& Spinhoven, Ph. (2012). General, specific and unique cognitive factors involved in anxiety and depressive disorders. Cognitive Therapy Research, 36, 621-633. http://dx.doi.org/10.1007/s10608-011-9401-z

Dunbar, G. C., \& Lishman, W. A. (1984). Depression, recognitionmemory and hedonic tone: A signal detection analysis. British Journal of Psychiatry, 144, 376-382. http://dx.doi.org/10.1192/bjp.144.4.376

Elliott, C. L., \& Greene, R. L. (1992). Clinical depression and implicit memory. Journal of Abnormal Psychology, 101, 572-574. http://dx.doi.org/10.1037//0021-843X.101.3.572

Ellwart, T., Rinck, M., \& Becker, E. S. (2003).Selective memory and memory deficits in depressed inpatients. Depression and Anxiety, 17, 197-206. http://dx.doi.org/10.1002/da.10102

Fossati, P., Coyette, F., Ergis, A.-M., \& Allilaire, J.-F. (2002). Influence of age and executive functioning on verbal memory of inpatients with depression. Journal of Affective Disorders, 68, 261-271. http://dx.doi.org/10.1016/S0165-0327(00)00362-1

Fossati, P., Ergis, A.-M., \& Allilaire, J.-F. (2002). Executive functioning in unipolar depression: A review. L'Encéphale, 28, 97-107.

Fossati, P., Harvey, P. O., Le Bastard, G., Ergis, A.-M., Jouvent, R., \& Allilaire, J.-F. (2004). Verbal memory performance of patients with a first depressive episode and patients with unipolar and bipolar recurrent depression. Journal of Psychiatric Research, 38, 137-144. http://dx.doi.org/10.1016/j.jpsychires.2003.08.002

Gardiner, J. M., \& Java, R. I. (1993). Recognition memory and awareness: An experiential approach. European Journal of Cognitive Psychology, 5, 337-346. http://dx.doi.org/10.1080/09541449308520122

Golinkoff, M., \& Sweeney, J. A. (1989). Cognitive impairments in depression. Journal of Affective Disorders, 17, 105-112. http://dx.doi.org/10.1016/0165-0327(89)90032-3

Gotlib, I. H., \& Joormann, J. (2010). Cognition and depression: Current status and future directions. Annual Review of Clinical Psychology, 6, 285-312. http://dx.doi.org/10.1146/annurev.clinpsy.121208.131305

Graf, P., \& Schacter, D. L. (1985). Implicit and explicit memory for new associations in normal and amnesic subjects. Journal of Experimental Psychology: Learning, Memory and Cognition, 11, 501-518. 
http://dx.doi.org/10.1037//0278-7393.11.3.501

Hartlage, S., Alloy, L. B., Vazquez, C., \& Dykman, B. (1993). Automatic and effortful processing in depression. Psychological Bulletin, 113, 247-278. http://dx.doi.org/10.1037//0033-2909.113.2.247

Hertel, P. T., \& Hardin, T. S. (1990). Remembering with and without awareness in a depressed mood: Evidence of deficits in initiative. Journal of Experimental Psychology: General, 119, 45-59. http://dx.doi.org/10.1037//0096-3445.119.1.45

Hertel, P. T., \& Milan, S. (1994). Depressive deficits in recognition: Dissociation of recollection and familiarity. Journal of Abnormal Psychology, 103, 736-742. http://dx.doi.org/10.1037/0021-843X.103.4.736

Hertel, P. T., \& Rude, S. S. (1991). Depressive deficits in memory: Focusing attention improves subsequent recall. Journal of Experimental Psychology: General, 120, 301-309. http://dx.doi.org/10.1037//0096-3445.120.3.301

Henry, G. M., Weingartner, H., \& Murphy, D. L. (1973). Influence of affective states and psychoactive drugs on verbal learning and memory. American Journal of Psychiatry, 130, 966-971.

Ilsley, J. E., Moffoot, A. P. R., \& O'Carroll, R. E. (1995). An analysis of memory dysfunction in major depression. Journal of Affective Disorders, 35, 1-9. http://dx.doi.org/10.1016/0165-0327(95)00032-I

Jacoby, L. L. (1991). A process dissociation framework: Separating automatic from intentional uses of memory. Journal of Memory and Language, 30, 513-541.

http://dx.doi.org/10.1016/0749-596X(91)90025-F

Jenkins, W., \& McDowall, J. (2001). Implicit memory and depression: An analysis of perceptual and conceptual processes. Cognition and Emotion, 15, 803-812.

http://dx.doi.org/10.1080/02699930143000220

Johnson, M. H., \&Magaro, P. A. (1987). Effects of mood and severity on memory processes in depression and mania. Psychological Bulletin, 101, 28-40. http://dx.doi.org/10.1037//0033-2909.101.1.28

Johnston, W. A., Dark, V. J., \& Jacoby, L. L. (1985). Perceptual fluency and recognition judgments. Journal of Experimental Psychology: Learning, Memory and Cognition, 11, 3-11.

http://dx.doi.org/10.1037/0278-7393.11.1.3

Kintsch, W. (1970). Models for free recall and recognition. In D. A. Norman (Ed.), Models of human memory (pp. 331-373). New York: Academic Press.

Lee, R. S. C., Redoblado-Hodge, M. A., Naismith, S. A., Hermens, D. F., Porter, M. A., \& Hickie, I. B. (2013). Cognitive remediation improves memory and psychosocial functioning in first-episode psychiatric out-patients. Psychological Medicine, 43, 1161-1173. http://dx.doi.org/10.1017/S0033291712002127

MacQueen, G. M., Galway, T. M., Hay, J., Young, L. T., \& Joffe, R. T. (2002). Recollection memory deficits in patients with major depressive disorder predicted by past depressions but not current mood state or treatment status. Psychological Medicine, 32, 251-258. http://dx.doi.org/10.1017/S0033291701004834

Mandler, G. (1980). Recognizing: The judgement of previous occurrence. Psychological Review, 87, 252-271.

http://dx.doi.org/10.1037//0033-295X.87.3.252

Miller, E., \& Lewis, P. (1977). Recognition memory in elderly patients with depression and dementia. Journal of AbnormalPsychology, 86, 84-86. http://dx.doi.org/10.1037//0021-843X.86.1.84

Mulligan, N. W. (2011). Implicit memory and depression: Preserved conceptual priming in subclinicaldepression. Cognition and Emotion, 25, 730-739. http://dx.doi.org/10.1080/02699931.2010.500479

Partiot, A., Pierson, A., Le Houezec, J., Dodin, V., Renault, B., \& Jouvent, R. (1993). Loss of automatic processes and blunted-affect in depression: A P3 study. EuropeanPsychiatry, 8, 309-318.

Partiot, A., Pierson, A., Renault, B., Widlöcher, D., \& Jouvent, R. (1994). Traitement automatique de l'information, système frontal et émoussement affectif. De la clinique dimensionnelle aux processus cognitifs, vers une psychobiologie des tempéraments. L'Encéphale, 20, 511-519.

Pierson, A., Partiot, A., Jouvent, R., Bungener, C., Martinerie, J., Renault, B., \& Widlöcher, D. (1994). Loss of control of pre-motor activation in anxiousagitated and impulsive depressives. A clinical and ERP study. Progress in Neuro-Psychopharmacology and Biological Psychiatry, 18, 1037-1050. http://dx.doi.org/10.1016/0278-5846(94)90129-5

Rabin, J. S., Carson, N., Gilboa, A., Stuss, D. T., \& Rosenbaum, R. S. (2013). Imagining other people's experiences in a person with impaired episodic memory: The role of personalfamiliarity. Frontiers in Psychology, 3, 588.

http://dx.doi.org/10.3389/fpsyg.2012.00588

Ramponi, C., Barnard, P. J., \& Nimmo-Smith, I. (2004). Recollection deficits in dysphoricmood: An effect of shematicmodels and executive mode? Memory, 12, 655-670.

http://dx.doi.org/10.1080/09658210344000189

Roediger III, H. L., \& McDermott, K. B. (1992). Depression and implicit memory: A commentary. Journal of Abnormal Psychology, 101, 587-591. http://dx.doi.org/10.1037//0021-843X.101.3.587

Roy-Byrne, P. P., Weingartner, H., Bierer, L. M., Thompson, K., \& Post, R. M. (1986). Effortful and automatic cognitive processes in depression. Archives of General Psychiatry, 43, 265-267.

http://dx.doi.org/10.1001/archpsyc.1986.01800030083008

Schatzberg, A. F., Posener, J. A., DeBattista, C., Kalehzan, B. M., Rothschild, A. J., \& Shear, P. K. (2000). Neuropsychological deficits in psychotic versus nonpsychoticmajordepressionandno mental illness. American Journal ofPsychiatry, 157, 1095-1100. http://dx.doi.org/10.1176/appi.ajp.157.7.1095

Schaub, A., Neubauer, N., Mueser, K. T., Engel, R., \& Möller, H. J. (2013). Neuropsychological functioning in inpatients with major depression or schizophrenia. BMC Psychiatry, 13, 203. http://dx.doi.org/10.1186/1471-244X-13-203

Schwartz, B. L., Rosse, R. B., \& Deutsch, M. D. (1993). Limits of the processing view in accounting for dissociations among memory measures in clinical population. Memory and Cognition, 21, 63-72. http://dx.doi.org/10.3758/BF03211165

Sperduti, M., Martinelli, P., Kalenzaga, S., Devauchelle, A. D., Lion, S., Malherbe, C., Gallarda, T., Amado, I., Krebs, M.-O., Oppenheim, C., \& Piolino, P. (2013). Don’t be too strict with yourself! Rigid negative self-representation in healthy subjects mimics the neurocognitive profile of depression for autobiographical memory. Frontiers in Behavioral Neuroscience, 7, 41.

http://dx.doi.org/10.3389/fnbeh.2013.00041

Sternberg, D. E., \& Jarvik, M. E. (1976). Memory functions in depression. Archives of General Psychiatry, 33, 219-224. http://dx.doi.org/10.1001/archpsyc.1976.01770020055009

Stromgren, L. S. (1977). The influence of depression on memory. Acta Psychiatria Scandinavica, 56, 109-128.

http://dx.doi.org/10.1111/j.1600-0447.1977.tb06670.x

Tarsia, M., Power, M. J., \& Sanavio, E. (2003). Implicit and explicit memory biases in mixed anxiety-depression. Journal of Affective Disorders, 77, 213-225. http://dx.doi.org/10.1016/S0165-0327(02)00119-2

Tulving, E. (1985). Memory and consciousness. Canadian Psychology, 26, 1-11. http://dx.doi.org/10.1037/h0080017

Watts, F. N., Dalgleish, T., Bourke, P., \& Healy, D. (1990). Memory deficits in clinical depression: Processing resources and the structure of materials. Psychological Medicine, 20, 345-349. http://dx.doi.org/10.1017/S0033291700017657

Weingartner, H., Cohen, R. M., Murphy, D. L., Martello, J., \& Gerdt, C. (1981). Cognitive processes in depression. Archives of General Psychiatry, 38, 42-47.

http://dx.doi.org/10.1001/archpsyc.1981.01780260044004 